\title{
Using Third-Party Evaluations to Assess Socioemotional Skills in Graduate School Admissions
}

\author{
David Klieger $^{1 *}$, Jennifer Bochenek ${ }^{1}$, Chelsea Ezzo ${ }^{1}$, Steven Holtzman ${ }^{1}$, \\ Frederick Cline $^{1}$, Margarita Olivera-Aguilar ${ }^{1}$
}

\footnotetext{
${ }^{1}$ ETS, Princeton, New Jersey, United States

* Corresponding author
}

(C) 2021, 2022 Taylor \& Francis Group, LLC. This paper and its supplemental materials are not the copies of record and may not exactly replicate the final, authoritative version of the article and its supplemental materials. Please do not copy or cite without authors' permission. The final article will be available, upon publication, via its DOI: 10.1080/15305058.2021.2019748.

\section{Author Note:}

The supplemental materials for this article are available in the OSF https://osf.io/agqk2.

Correspondence concerning this article should be addressed to David Klieger, ETS, 660 Rosedale Road, MS 09-R, Princeton, New Jersey 08541, United States. Telephone: +01-609-734-1977. Email:

\section{dklieger@ets.org}

We wish to thank Drs. Patrick Kyllonen, Jesse Sparks, Brent Bridgeman, and Michael Walker for their technical guidance that improved this manuscript. The authors wish to thank also the six graduate institutions and their programs that worked diligently to provide us with data. We also appreciate the support of the Global Higher Education Program at ETS, including Alberto Acereda, Walter Jiménez and Kathryn Pedley. 


\begin{abstract}
Consideration of socioemotional skills in admissions potentially can increase representation of racial and ethnic minorities and women in graduate education as well as identify candidates more likely to succeed in graduate school. Research on one such assessment, the ETS Personal Potential Index (PPI), showed that the PPI produced much smaller racial/ethnic-gender group mean score differences than undergraduate grade point average (UGPA) and the Graduate Record Examinations (GRE) did. Across levels of institutional selectivity, the PPI can promote racial/ethnic and gender diversity in graduate and professional school in ways that UGPA and GRE scores do not. Predictive validity analyses showed that for doctoral STEM programs the PPI dimensions of (i) Planning and Organization and (ii) Communication Skills positively predict graduate school grade point average as well as a lower risk of academic probation, a determinant of degree progress, both alone and incrementally over UGPA and GRE scores.
\end{abstract}

Keywords: Admissions, graduate school, third-party evaluation, other-report, observer rating, letter of recommendation, recommendation letter, reference letter, reference, observer, rater, ratee, socioemotional, soft skills, noncognitive, non-cognitive, social, psychosocial, personality, behavioral, $21^{\text {st }}$ Century skills, knowledge, creativity, communication, teamwork, resilience, planning, organization, ethics, integrity, fairness, diversity, equity, inclusion, race, ethnicity, gender, validity, predict, reliability, PPI, Personal Potential Index, GRE, Graduate Record Exam, grades, grade point average, degree progress, degree completion, standardize, leniency bias 


\section{Introduction}

In order for use of an assessment to be warranted in high-stakes selection decisions, it should not only enhance diversity, but also show evidence of predictive validity. Use of an assessment that lacks predictive validity but increases the likelihood of admissions for members of one demographic group might raise various fairness, ethical, and legal concerns (American Educational Research Association et al., 2014; Society for Industrial and Organizational Psychology, 2018). However, enhancing diversity while maintaining or improving the prediction of graduate and professional school outcomes can be challenging. Pyburn, Ployhart, and Kravitz (2008) coined the term "the diversityvalidity dilemma" to describe the long-known difficulties in simultaneously maximizing both diversity and predictive validity of a selection system that includes cognitive skills assessments, including standardized admission tests.

One way to address the "diversity-validity dilemma" is to combine socioemotional predictors with more cognitive ones (e.g., undergraduate grade point average [UGPA] and GRE) in the admissions decision making process in the belief that the socioemotional predictors will contribute to predictive validity while diluting (if not offsetting) the cognitive assessments' potential effect on racial/ethnic and gender diversity. Findings from empirical research suggest that socioemotional assessment used in conjunction with cognitive assessment in higher educational admissions can contribute simultaneously to the prediction of valued outcomes and racial/ethnic and gender diversity (see, e.g., Schmitt et al., 2009, Shultz \& Zedeck, 2011). This strategy has not always succeeded, at least not in analogous hiring contexts (see, e.g., Ryan, Ployhart \& Friedel, 1998; Schmitt et al., 1997); simulations by Sackett and Ellingson (1997) statistically illuminate why this approach does not always succeed, irrespective of whether the context is admissions or hiring. 
The most ubiquitous measure of graduate school applicants' socioemotional qualities arguably is the letter of recommendation, which is widely used in graduate school admissions. For graduate school, recommendation letters predict graduate school performance based on scores that letter writers provide for the applicants' qualities about which they have written $(r=.15)$, faculty performance ratings $(r=.25)$, Ph.D. attainment ( $r=.19)$, and research productivity ( $r=.10$; Kuncel et al., 2014). Letters are intercorrelated with other admissions predictors such as GRE Verbal Reasoning scores $(r=.14)$, Quantitative Reasoning scores ( $r=.08)$, prior grade point average $(r=.26)$, personal statements $(r=.41)$, and interviews ( $r=.18$; Kuncel et al., 2014). While letters of recommendation demonstrate almost no incremental predictive validity over GRE scores and UGPA for predicting grade point average or faculty ratings $\left(\Delta R^{2}=.003, .011\right)$, they do provide some incremental validity over GRE scores and UGPA for predicting degree attainment $\left(\Delta R^{2}=.024 ;\right.$ Kuncel, Kochevar, \& Ones, 2014).

Letters of recommendation have faced various validity and diversity challenges. Levels of interrater reliability for letters of recommendation are variable across studies but low on average, often failing to exceed .40 where there are the traditional number of three writers or letter raters (see Baxter et al., 1981; Mosel \& Goheen, 1959; Rim, 1976). This ceiling on reliability limits predictive validity (Nunnally, 1978). In addition, there are concerns about gender or racial bias in the content and interpretation of recommendation letters, where bias can favor or disfavor historically underrepresented groups (Dalal et al., 2021; Filippou et al., 2019; Lin et al., 2019; Madera et al., 2009, 2019; Morgan et al., 2013). Since recommendation letters are intended to inform highly consequential selection decisions, some have advised that the letters be standardized to address reliability, validity, bias, and fairness issues (Dalal et al., 2021; Kim \& Kyllonen, 2006; Kyllonen et al., 2005; Liu et al., 2009).

The study discussed below examines group mean score differences, potentially resulting diversity impacts and predictive validity for the Personal Potential Index (PPI), an assessment that 
standardizes aspects of the traditional letter of recommendation used in graduate and professional school admissions. The standardized aspects of the PPI are described below. The PPI had been designed to be predictive of graduate and professional school performance and progress - and beyond what UGPA and standardized tests already can predict - without resulting in notably lower average scores observed for groups underrepresented generally or in certain areas of higher education.

\section{Hypotheses}

Given the foregoing simultaneous diversity and validity attainment goals, we investigated the following three hypotheses for the PPI as a socioemotional assessment for use in graduate and professional school admissions context:

1. The differences between the mean scores of Black and Hispanic groups compared to White and Asian groups, and the female group compared to the male group, are greater on the GRE General Test and UGPA (more cognitively-based skills) than on the PPI (socioemotional skills). ${ }^{1}$

Despite empirical evidence of Graduate Record Examinations (GRE) validity (Klieger et al., 2014; Kuncel \& Hezlett, 2007; Kuncel et al., 2001, 2010) and lack of GRE test and prediction bias (see Braun \& Jones, 1985; Burton \& Wang, 2005; Educational Testing Service, 2020a; Robin, 2014), longstanding concerns about racial/ethnic and gender groups' average score differences on the GRE persist (see, e.g., Miller \& Stassun, 2014; Posselt, 2016; Sedlacek, 2004). While these differences and their consequences for a well-validated and carefully scrutinized test are not indications of test or prediction bias, they often lead to discussion about admissions systems and the pre-existing historical and societal factors that led to these differences, such as unequal learning opportunities across disparately-funded primary and

\footnotetext{
${ }^{1}$ As with all groups, the Asian group consists of subgroups that could be considered underrepresented in graduate school (southeast Asian). However, we lacked the data to examine these subgroups separately.
} 
secondary school systems as well as expectations based on stereotypes (Barton \& Coley, 2009; Warne et al., 2014; Woo et al., 2020). Across standardized tests, the average score of White individuals generally has been about one standard deviation higher than the average score of Black individuals; the average score of White individuals has been higher than the average score of Hispanic individuals to a lesser extent; and Asian examinees typically have performed at least as well as White examinees, especially on assessments of quantitative skills; for U.S. citizens applying to college or graduate school, women have tended to underperform men on assessments of quantitative and certain verbal reasoning skills (see $A$ Snapshot, 2020; Gallagher et al., 2002; Hunter \& Hunter, 1984; Schmitt et al., 1996). Personality-based assessments tend not to show such large differences (see, e.g., Foldes, Duehr, \& Ones, 2008). It is possible that stereotypical expectations and fewer formal educational opportunities are less likely to detract from the acquisiton of socioemotional skills than more cognitive ones, and they might force individuals to develop additional personal strengths in order to carry on.

2. Under top-down selection, increased use of the PPI will increase admissions rates for groups underrepresented generally or in certain areas of graduate education.

Without a truly holistic admissions process, score differences can reduce substantially the percentage of Black and Hispanic individuals admitted to institutions of higher education in comparison to the percentage of White and Asian individuals admitted; the same observation can be made for the percentage of female individuals admitted to graduate programs where they tend to be underrepresented (e.g., some STEM fields; Okahana et al., 2020). Based on a top-down method of selection (where the applicant with the highest score is the first admitted, the applicant with the second-highest score is next admitted, and so on), with a one-half standard deviation group difference in mean scores, 2.6 times as many members of the higher-scoring group would be chosen by highly selective institutions; 1.6 times as many members of the higher-scoring group would be chosen by 
selective institutions; and 1.2 times as many members of the higher-scoring group would be chosen by less-selective institutions (see Sackett \& Ellingson, 1997). These effect sizes respectively jump to 7.7, 3.1, and 1.5 times in favor of the higher scoring group when the mean difference in scores is a full standard deviation (Sackett \& Ellingson, 1997). ${ }^{2}$

3. The PPI predicts graduate grade point average (GGPA) and degree progress across graduate degree levels (doctoral and masters) and areas (STEM and non-STEM), and it provides incremental prediction of these criteria over and above what the GRE and UGPA predict.

The leading models of work performance include distinct socioemotional performance dimensions or factors (e.g., Campbell's [2012] demonstrating effort and Borman and Motowidlo's contextual performance [1997]), in addition to more cognitive ones. Thus, it is reasonable to believe that the PPI would add to prediction of work performance over and above what more cognitive measures predict.

\section{Methods}

\section{Measures}

The PPI . The PPI is a web-based, multi-rater system for evaluating the socioemotional skills of applicants to graduate and professional school. It became operational in 2009 , but since it was not widely used for graduate school admissions it was discontinued in 2016. The PPI is more standardized than an open-ended, qualitative reference letter, as third parties selected by the applicants use the PPI

\footnotetext{
${ }^{2}$ Not all admissions decisions employ a purely top-down selection process, where the applicant with the highest score is the first admitted or funded, the applicant with the second-highest score is the next one admitted or funded, and so on (see, e.g., discussion in Walpole, Burton, Kanyi, \& Jackenthal, 2002). However, contrary to ETS support of holistic admissions practices (Educational Testing Service, 2020b), at least some graduate programs have used GRE cut scores (Posselt, 2016). When setting a cut score, some degree of rank ordering is required. Top-down selection represents the most acute use of cut scores and, all other things being equal, will exacerbate the impact of average group score differences on admission rates of historically underrepresented groups.
} 
to provide quantitative (5-point Likert scale) and qualitative evaluations of the applicants on six dimensions that subject matter experts had concluded were important determinants of graduate and professional student success (with four items per dimension): Knowledge and Creativity, Communication Skills, Teamwork, Resilience, Planning and Organization, and Ethics and Integrity (see the dimensions with their respective items in Appendix A), as well as in an Overall assessment item. Before providing PPI ratings, evaluators are prompted with the following comparative anchor: "Please rate the applicant relative to others in your department or unit who have gone on to graduate or professional study." In order to address concerns about possible rater leniency bias, "Top 1\%" expressly appeared as part of the descriptive anchor for the highest rating of 5, "Top 5\%" for a rating of 4, "Above Average" for a rating of 3, "Average" for a rating of 2 , and "Below Average" for the lowest rating of $1 .{ }^{3}$ In addition to giving quantitative appraisals, evaluators were able to provide qualitative assessments for each dimension by typing comments into text boxes. Kyllonen (2008) describes the development of the PPI.

The Graduate Record Examinations General Test (GRE) . The GRE is a standardized assessment of cognitive skills used in graduate and professional school admissions and funding decisions. The test consists of a multiple-choice section that assesses verbal reasoning skills (GRE-Verbal, or GRE-V), a multiple-choice section that assesses quantitative reasoning skills (GRE-Quantitative, or GRE-Q), and a constructed response section that assesses analytical writing skills (GRE-Analytical Writing, or GRE-AW). GRE test scores used in this study are from the years 2007 to 2015 . Given changes to the GRE-V and GRE-Q score scales in August 2011, GRE-V and GRE-Q scores from the GRE taken prior to August 2011 were converted to the current GRE-V and GRE-Q score scales. Thus, the scores for GRE-V and GRE-Q analyzed in this study ultimately were on a 130 to 170-point scale, with one-point increments. All scores

\footnotetext{
${ }^{3}$ For two of the 25 PPI items, the response options instead were "Very Strongly Agree", "Strongly Agree", "Agree", "Disagree", and "Strongly Disagree".
} 
for GRE-AW were on a 1-6 scale, with 0.5-point increments. Minimum discriminant information adjustment retest reliabilities for GRE-V and GRE-Q were reported as 0.75 and 0.83 , respectively, and as 0.75 for GRE-AW (Haberman \& Yao, 2015).

UGPA. UGPA has been traditionally considered to be a measure of both cognitive and socioemotional constructs. In addition to cognitive skills, UGPA reflects motivation, perseverance, study habits, time management, realistic self-appraisal of one's work, class attendance, completion of assignments, and other behaviors that are not purely intellective in nature (see discussion in Borghans et al., 2016; Bowen et al., 2009; Camara, 2005; Camara et al., 2003; Farrington et al., 2012; McAbee, et al., 2014). We obtained self-reported UGPAs for those applicants who both used the PPI and registered for the GRE. UGPA had been reported previously on the questionnaire administered as a standard part of GRE test registration and was based on the following set of categorical response options to a multiple-choice question: $\mathrm{A}, \mathrm{A}-, \mathrm{B}+, \mathrm{B}, \mathrm{B}-, \mathrm{C}+$, and $\mathrm{C}$ or lower. Using the commonplace U.S. conversion scale (College Board, 2021), we translated these category selections into numerical values, as follows: A $=4, \mathrm{~A}-=3.7, \mathrm{~B}+=3.3, \mathrm{~B}=3, \mathrm{~B}-=2.7, \mathrm{C}+=2.3$, and $\mathrm{C}$ or lower $=2$. When possible, we examined UGPA for undergraduate major in addition to overall (i.e., cumulative) UGPA.

GGPA. We obtained GGPA from the programs participating in the study. GGPA used the same scale as UGPA but allowed for grades below a C (College Board, 2021). GGPA is not a measure purely of intellective behaviors, as it reflects some of the same socioemotional behaviors that UGPA does (see Verostek et al., 2021). A GGPA falling below a B can result in academic probation at many US institutions (Seligman, 2012).

\section{Samples}

Our study consisted of three dependent samples that maximized the amount of data available for analysis: For diversity analyses, we used records for 6,414 graduate and professional school 
applicants who have received PPI ratings between 2009 and 2016 and GRE General Test scores between 2007 and 2015. Applicants were all U.S. citizens who self-reported their gender as male or female and their race/ethnicity as Asian, Black, Hispanic, or White). Individuals who self-reported as American Indian or Native American, or as Hawaiian or Other Pacific Islander, were not included due to their extremely small sample sizes. For validity analyses, data came from a subset of the sample for diversity and reliability analyses (see Table S2 in supplemental materials, pages 17-18 for reliability analyses). This subset ultimately consisted of 694 students enrolled in one of 33 doctoral or masters programs across six geographically diverse, medium- to large-sized, public and private, U.S. universities. The Carnegie classification for five of these universities was high research activity, and for the sixth it was very high research activity. One of the six was a historically Black university. Each program contained at least eight individuals with complete data. Table 1 describes the validity sample.

\section{Statistical Methods}

In order to examine Hypothesis 1, we calculated Cohen's $d$ values (using pooled variances) and computed their $95 \%$ confidence intervals. In all comparisons, Cohen's $d$ was computed such that a positive value indicates that the minority group had the higher mean score.

Regarding Hypothesis 2, we created composites as the sum of z-scores across different combinations of PPI, GRE, and UGPA scores. We simulated decisions based on top-down admissions rates selecting the top $15 \%, 25 \%$, and $50 \%$ of applicants and examined the proportion of individuals from underrepresented groups who would be admitted.

Hypothesis 3 concerns the predictive validity of the PPI. Because reliability values set the ceiling of the possible values for predictive validity, we first examined the interrater reliability of the PPI. In addition to examining the relationship between the PPI and GGPA, we dichotomized GGPA in order to examine the relationship between PPI and receipt of a grade lower than B. We were interested in 
grades lower than B as an outcome, as in many institutions these grades can result in academic probation (Seligman, 2012) and, hence, they can be used as one indicator of a lack of degree progress.

Our first predictive validity analyses entailed calculating zero-order correlations between PPI ratings and GGPA and between PPI ratings and receiving a grade lower than a $\mathrm{B}$. These correlations were computed as aggregated point estimates obtained by first adjusting each program's correlation to account for the effect of range restriction, then weighting each program's adjusted correlation by the program's sample size, and then calculating a sample-size weighted average across programs.. To our knowledge, programs did not use the PPI to make admissions decisions, but we understood that they used GRE scores and UGPA to do so. Therefore, correlations where GRE and UGPA were the predictors were adjusted to account for the effect of direct range restriction (Thorndike [1949] Case II). Furthermore, correlations where PPI dimensions were the predictors were adjusted to account for the effect of indirect range restriction (Thorndike [1949] Case III). To examine the incremental validity of the PPI over and above UGPA and the GRE, and to account for the clustered nature of the data (students nested within programs), hierarchical linear modeling (HLM; see supplemental materials on page 19 for detailed methodology) was used in the prediction of GGPA, and generalized estimating equation (GEE) logistic regression was used in the prediction of a grade lower than B (see supplemental materials on pages 19-20 for detailed methodology). Analyses were conducted at an aggregate level, because there were too few doctoral STEM clusters large enough to conduct a more granular analysis.

\section{Results}

\section{Hypothesis 1: Mean differences on PPI vs. GRE and UGPA}

Our first hypothesis was that the differences between the mean scores of groups underrepresented generally or in certain areas of graduate education -- specifically Black, Hispanic, and 
female individuals -- and the mean scores of White, Asian, and male individuals would be smaller on the PPI than on the GRE and UGPA. Our results in Table 2 show that this hypothesis was supported.

For the PPI assessments of socioemotional skills, the $d$ values describing mean differences between the Black group and White group were relatively small $(-0.09 \leq d s \leq 0.12)$, and the mean scores for the Black group on the dimensions of Teamwork, Resilience, and Ethics and Integrity were higher than they were for the White group ( $d s=0.12,0.06$, and 0.03 , respectively), with the difference for Teamwork being statistically significant. Observed mean scores for the Hispanic group on all socioemotional dimensions (including the Overall rating) were higher than they were for the White group $(0.004$ [before rounding to 0.00 ] $\leq d s \leq 0.08)$, but none were statistically or practically significant.

Cohen's $d$ values for mean comparisons between the Black group and the White group on the GRE were -0.84 for GRE-V, -1.12 for GRE-Q, and -0.73 for GRE A-W. Values of Cohen's $d$ for mean comparisons between the Hispanic group and the White group on the GRE were -0.44 for GRE-V, -0.32 for GRE-Q, and -0.41 for GRE A-W. Given the impact of differences in groups' mean scores on admission rates of lower-scoring groups (as described in Sackett and Ellingson, 1997), the $d$ values for both the Black group and Hispanic group were practically significant.

The result for minority admission rates from using overall or major UGPA in top-down decisionmaking is similar to the result of using GRE scores. As shown in Table 2, the White group uniformly had on average higher UGPAs (both overall and major) than all other groups, including the Asian group. Differences $(-0.76 \leq d s \leq-0.27$ for overall UGPA, $-0.64 \leq d s \leq-0.34$ for major UGPA) were large enough to be statistically and practically significant (see Sackett \& Ellingson, 1997). We also examined differences between self-identified male and female gender groups (Table S1 and Figures S1-S5 in the supplemental materials, pages 3-8).

\section{Hypothesis 2: PPI's effect on admissions rates for underrepresented minorities}


Our second hypothesis, that use of socioemotional measures would increase admissions rates for minorities underrepresented generally or in some areas of graduate education, was supported. Across selection rates in top-down admissions, increased use of PPI dimensions consistently led to a higher admissions rate for groups underrepresented generally or in certain areas of graduate education. Figure 1 illustrates our findings for a 15\% admission rate with PPI Planning and Organization as the socioemotional measure. In this instance, Black female candidates comprise $6 \%$ of the applicant pool. In contrast, admissions based solely on GRE and UGPA ("100\% GRE + UGPA") would result in only $1 \%$ of the admitted pool consisting of Black female candidates. For admissions based on $50 \%$ weighting of GRE plus UGPA (" $50 \%$ GRE+UGPA") and 50\% weighting of the PPI Planning \& Organization dimension (" $50 \%$ PPI P\&O"), $2 \%$ of the admitted applicant pool would consist of Black female candidates. For admissions based $100 \%$ on the PPI Planning \& Organization dimension (“100\% PPI P\&O"), $6 \%$ of the admitted applicant pool would consist of Black female candidates. Figures S6-S17 are included in the Supplemental Materials where interested readers will observe a very similar pattern for other admission rates and for PPI-Communication Skills.

The foregoing admission rates might differ in a more holistic admissions system, but how realworld admissions operates is variable and often opaque (Posselt, 2016). Changing the composite weights might affect predictive validity. Below, we identify which measures would be expected to contribute to predictive validity using regression weights.

\section{Hypothesis 3: PPI's prediction of GGPA and degree progress}

Our third hypothesis, for which we found partial support, was that the PPI predicts GGPA and degree progress, and that it provides incremental prediction of these outcomes over and above what GRE and UGPA collectively predict. Overall, we found that evaluators are not providing radically different appraisals of candidates on each dimension. In general, PPI interrater reliability (.35-.43 for 3 
raters), which mathematically places a ceiling on criterion-related validity (Nunnally, 1978), was similar to the .40 reliability values that have been reported for reference letters (see Baxter et al., 1981; Mosel \& Goheen, 1959; Rim, 1976; due to space limitations, reliability results are discussed in more detail in the supplemental materials, pages 17-18).

Table 3 shows the zero-order correlations overall and by degree level (doctorate and masters) and area (STEM and non-STEM). For grade below a B, a negative correlation indicates that higher performance on the predictor is associated with lower frequency of receiving a graduate school grade below a B. There were statistically significant relationships ( $95 \%$ confidence intervals omitting 0 ) between PPI Communication Skills and Planning and Organization with both outcomes for doctoral STEM programs (for predicting GGPA, adj $r=.16$ and .17 , respectively; for predicting grade below a B, adj $r=-.21$ and -.19 , respectively; see Table 3). PPI Planning and Organization had a statistically significant correlation with GGPA for programs generally but likely because of its predictive power for doctoral STEM programs. There were no other statistically significant zero-order correlations for PPI. For the GRE, statistically significant findings were common for predicting GGPA. Notably, for doctoral programs - for which validity for PPI Communication Skills and Planning and Organization was statistically significant for both outcomes - only GRE-Q demonstrated a statistically significant correlation, and only for predicting GGPA (adj $r=.22$; see Table 3 ). UGPA was the most frequently statistically significant and strongest predictor of both outcomes.

Furthermore, Table 4 shows that the redundancy (i.e., intercorrelations) between GRE and PPI dimensions and between UGPA and PPI dimensions are small enough ( $|r| \leq .18$ and $|r| \leq .24$, respectively) to allow the PPI's socioemotional dimensions to have practically significant incremental validity for predicting outcomes. There are several identifiable types of knowledge, skills, abilities, and motivational drivers (KSAs) that a student usually needs to possess in order to succeed in graduate or professional 
school (see Borman \& Motowidlo, 1997; Campbell, 2012; Enright \& Gitomer, 1989; Kyllonen et al., 2005; Oswald et al., 2004). UGPA and the GRE measure a subset of these KSA constructs. Admissions committees generally want to know about other parts of this KSA network, too, because the inclusion of new information potentially can help admissions committees make more accurate predictions of whether an applicant will succeed in graduate or professional school.

We therefore also directly investigated whether PPI predicted GGPA or receiving a grade below a B above and beyond the validity of GRE and UGPA to predict these outcomes. The HLM results for the prediction of GGPA show that PPI ratings explain $2.23 \%$ of within-program variance after controlling for UGPA and GRE scores (see Table 5). Planning and Organization and Knowledge and Creativity were statistically significant PPI predictors $(\gamma=.12, p<.01$ and $\gamma=-.10 p<.05$, respectively), as were UGPA and GRE-Q ( $\gamma^{\prime} s=.14$ and .01 , respectively, both $\left.p^{\prime} s<.001\right)$ (see Table 5).

For the prediction of a grade lower than a B (Table 6), PPI Communication Skills (as well as PPI Knowledge and Creativity, UGPA, and GRE-AW) was a statistically significant predictor in a GEE logistic regression model consisting of UGPA, all GRE sections, and all PPI dimensions ( $p<.02$; see supplemental materials on pages 19-20 for detailed methodology). Based on odds ratios, a one-unit increase in PPI Communications Skills results in a $66 \%$ decrease in the likelihood of receiving a grade below a B after controlling for the effect of the other predictors. Counterintuitively, a one-unit increase in PPI Knowledge and Creativity results in a $302 \%$ increase in the likelihood of receiving a grade below a B. One possible explanation of this finding is that people who have a broad perspective on the field and are bright, creatively productive, and intensely curious about the field (see PPI Knowledge and Creativity items in Appendix A) tend not to focus on achieving concrete grade outcomes, and vice-versa. More research on this finding is necessary. One-unit increases of UGPA and GRE-AW result in $67 \%$ and $34 \%$ decreases, respectively. PPI Planning and Organization would have been statistically significant if the 
standard for statistical significance had been set at $p<.07$. Given previous diversity and validity findings for PPI Planning and Organization, if one is willing to accept a 7\% (beyond a conventional 5\%) risk that this validity finding is due to random error, then one would conclude that a one-unit increase in PPI Planning and Organization results in a $61 \%$ decrease in the likelihood of receiving a grade below a B. The rejection of statistical findings based on the $5 \%$ error risk convention has been considered to be an arbitrary convention (McShane et al., 2019).

\section{Discussion}

The research findings provide evidence for doctoral STEM programs that, when the GRE and UGPA also are being used in making admissions decisions (and they often are the only admissions information that is quantified), PPI Communication Skills and Planning and Organization can contribute to racial, ethnic, and gender diversity in the admissions process while contributing to the prediction of academic performance and degree progress. These empirical findings are largely consistent with prior research about what skills are thought to be important for success in graduate school. Based mainly on interviews with faculty, Enright and Gitomer (1989) and Walpole et al. (2002) identified communication as one of the most important skill sets of successful graduate students. Enright and Gitomer also identified Planning as a key skill set for successful graduate students. Kyllonen and Walters (2005) describe additional taxonomies of skills thought to be critical to graduate school performance which include communication and planning. Furthermore, Campbell (2012) describes job performance models in which communication and planning are key higher order determinants of work success. As indicated, more research is needed to understand the counterintuitive finding for PPI Knowledge and Creativity.

Our investigations have their limitations. Absence of evidence is not evidence of absence; although we did not find validity evidence for all socioemotional skill areas measured by the PPI, our findings should not be interpreted as indicating that socioemotional skills other than Communication 
and Planning and Organization are irrelevant to graduate and professional student success. Our findings might differ for other success outcomes that programs value (number of publications, leadership roles, etc.) or for different ways of assessing the other socioemotional skills such as use of multidimensional forced choice assessments (see Stark, Chernyshenko, \& Drasgow, 2012). Additionally, we did not look at all of the admissions information that a decision maker could consider in making admissions decisions for graduate and professional students (e.g., personal statements, interviews, etc.). For our analyses, we analyzed human decision-making using statistical optimization (top-down selection, correlation, and regression) when many admissions decision-makers might use more holistic and less statistical methods. In addition, Black individuals in our validity sample came primarily from the HBCU institution, and so as a group they might not fully represent Black individuals at other, especially predominantly White-serving, institutions.

Meta-analytic findings of Connelly and Ones (2010) suggest that the reliability and validity of the PPI (reliability reported in the supplemental materials on pages 17-18) can be improved. Their study demonstrated that third party evaluations of socioemotional qualities have potential to yield higher interrater reliability than observed for letters of recommendation (cf. Baxter et al., 1981; Mosel \& Goheen, 1959; Rim, 1976) and the PPI, especially when the relationship of the ratee to the evaluator is a close one. They also showed that third party evaluation has potential for predicting academic and job performance more strongly than the predictive validity observed for letters of recommendation (see Kuncel et al., 2014) and the PPI. PPI evaluators tended to have a leniency bias in their ratings despite self-reports that they were strict. Although the PPI rating scale attempted to offset expected leniency bias in ratings, the modal PPI item rating was 4 for most dimensions and Overall (it was 5 for Ethics and Integrity and for Teamwork), where the anchor for 4 is "Top 5\%" and for 5 "Top 1\%" (see Table 1). Ratings of 3 ("Average") were given at least $10 \%$ of the time except on Ethics and Integrity items. And 
we agree with McCaffrey, Oliveri, and Holtzman (2018) that achieving higher observed score reliability (higher variances attributable to the ratee) for the PPI is a desired goal.

Possible ways to improve observed score (and interrater) reliability include measuring new constructs, revising and increasing the number of items and scale points, changing the scale point anchor labels and the description of the person against whom ratees should be compared, setting a minimum number of evaluators per ratee, requiring that evaluators be those who know the ratee well on PPI dimensions and will evaluate them objectively, training the evaluators, rationing the use of high ratings, and including automated scoring of the textual evidence that evaluators provide for each PPI dimension (see Heilman et al., 2015). Proposed solutions will come with tradeoffs, such as some applicants being unable to increase the limited number of qualified evaluators available to assess them, possible evaluator resistance to the loss of autonomy associated with training and restricted scoring, and greater risk of measurement and operational error, more time commitment, and greater financial cost associated with having a more complex evaluation system.

\section{Conclusion}

Along with valid admissions information, decision makers in graduate admissions say that they also want greater racial/ethnic and gender diversity of their student bodies (see Walpole et al., 2002); yet many of them remain equivocal in their efforts to attain it (Posselt, 2016). At the same time, the "diversity-validity dilemma" has been tenacious (Pyburn et al., 2008). For skeptical graduate admissions faculty, this study indicates that use of a socioemotional measure can overcome this dilemma to contribute to a more diverse student body while simultaneously helping to select students who will succeed in graduate and professional school. 


\section{References}

A snapshot of the individuals who took the GRE revised General Test: August 2014-June 2019. (2020). Princeton, NJ: Educational Testing Service.

American Educational Research Association, American Psychological Association, National Council on Measurement in Education (2014). Standards for educational and psychological testing. American Educational Research Association.

Barton, P.E., \& Coley, R. J. (2009). Parsing the achievement gap II. Policy Information Report. Princeton, NJ: Educational Testing Service. Retrieved January 25, 2021 from https://www.ets.org/Media/Research/pdf/PICPARSINGIl.pdf

Baxter, J. C., Brock, B., Hill, P. C., \& Rozelle, R. M. (1981). Letters of recommendation: A question of value. Journal of Applied Psychology, 66, 296-301. https://doi.org/10.1037/0021-9010.66.3.296

Borghans, L., Golsteyn, B. H. H., Heckman, J. J., \& Humphries, J. E. (2016). What grades and achievement tests measure. Proceedings of the National Academy of Sciences of the United States of America, 113, 13354-13359. https://doi.org/10.1073/pnas.1601135113

Borman, W., \& Motowidlo, S. (1997). Task performance and contextual performance: The meaning for personnel selection research. Human Performance, 10(2), 99-109. https://doi.org/10.1207/s15327043hup1002_3

Bowen, W. G., Chingos, M. M., and McPherson, M. S. (2009). Crossing the finish line: Completing college at America's public universities. https://doi.org/10.1515/9781400888924-011

Braun, H. I., \& Jones, D. H. (1985). Use of empirical Bayes methods in the study of validity of academic predictors of graduate school performance. (Program Statistics Research Technical Report No. 84-48, Research Report No. 84-34, GRE Board Professional Report GREB No. 79-13).. https://doi.org/10.1002/j.2330-8516.1984.tb00074.x

Burton, N. W., \& Wang, M. M. (2005). Predicting long-term success in graduate school: A collaborative study (GRE Board Report No. 99-14R; ETS RR-05-03). Retrieved January 10, 2021 from http://www.ets.org/Media/Research/pdf/RR-05-03.pdf

Camara, W. J. (2005). Broadening criteria of college success and the impact of cognitive predictors. In W. J. Camara, and E. W. Kimmel (Eds.), Choosing students: Higher education admissions tools in the 21st century (pp. 52-80).

Camara, W., Kimmel, E., Scheuneman, J., \& Sawtell, E. A. (2003). Whose grades are inflated? (College Board Research Report No. 2003-4). College Entrance Examination Board.

Campbell, J. P. (2012). Behavior, performance, and effectiveness in the twenty-first century. In S. W. J. Kozlowski (Ed.), Oxford library of psychology. The Oxford handbook of organizational psychology, Vol. 1 (p. 159-194). Oxford University Press.

College Board. (2021, June 23). How to convert your GPA to a 4.0 scale. Retrieved November 10, 2021 from https://pages.collegeboard.org/how-to-convert-gpa-4.0-scale 
Connelly, B. S., \& Ones, D. S. (2010). Another perspective on personality: Meta-analytic integration of observers' accuracy and predictive validity. Psychological Bulletin, 136, 1092-1122. https://doi.org/10.1037/a0021212

Crenshaw, K. W. (1989). Demarginalizing the intersection of race and sex: A Black feminist critique of antidiscrimination doctrine, feminist theory and antiracist politics. University of Chicago Legal Forum 1989, 139-67.

Dalal, D. K., Randall, J. G., Cheung, H. K., Gorman, B. C., Roch, S. G., \& Williams, K. J. (2021). Is there bias in alternatives to standardized tests? An investigation into content differences in letters of recommendation by race, gender, and degree program. International Journal of Testing.

Educational Testing Service. (2020a). GRE test fairness and validity. Retrieved November 10, 2021 from https://www.ets.org/gre/revised general/about/fairness/

Educational Testing Service. (2020b). Navigating holistic admissions for a stronger graduate program. Retrieved November 10, 2021 from https://www.holisticadmissions.org/

Enright, M. K., \& Gitomer, D. H. (1989). Toward a description of successful graduate students (GRE Board Professional Report No. 89-09, GRE Board Research Report 85-17R). Princeton, NJ: Educational Testing Service. https://doi.org/10.1002/j.2330-8516.1989.tb00335.x

Farrington, C. A., Roderick, M., Allensworth, E., Nagaoka, J., Keyes, T. S., Johnson, D.W., \& Beechum, N.O. (2012). Teaching adolescents to become learners. The role of noncognitive factors in shaping school performance: A critical literature review. Chicago: University of Chicago Consortium on Chicago School Research.

Filippou, P., Mahajan, S., Deal, A., Wallen, E. M., Tan, H-J, Pruthi, R. S., Smith, A. B. (2019). The presence of gender bias in letters of recommendations written for urology residency applicants. Urology, 134, 56-61. https://doi.org/10.1016/j.urology.2019.05.065

Foldes, H. J., Duehr, E. E., \& Ones, D. S. (2008). Group differences in personality: Meta-analyses comparing five U.S. racial groups. Personnel Psychology, 61(3), 579-616. https://doi.org/10.1111/j.1744-6570.2008.00123.x

Gallagher, A., Bridgeman, B., \& Cahalan, C. (2002). The effect of computer-based tests on racial-ethnic and gender groups. Journal of Educational Measurement, 39, 133-147. https://doi.org/10.1111/j.1745-3984.2002.tb01139.x

Haberman, S., \& Yao, L. (2015). Repeater analysis for combining information from different assessments. Journal of Educational Measurement, 52, 223-251. https://doi.org/10.1111/jedm.12075

Heilman, M., Breyer, F. J., Williams, F., Klieger, D., \& Flor, M. (2015). Automated analysis of text in graduate school recommendations. ETS Research Report 15-23. Princeton, NJ: Educational Testing Service. https://doi.org/10.1002/ets2.12070

Hunter, J. E., \& Hunter, R. F. (1984). Validity and utility of alternative predictors of job performance. Psychological Bulletin, 96, 72-98. https://doi.org/10.1037/0033-2909.96.1.72 
Kim, S., \& Kyllonen, P. C. (2008). Rasch measurement in developing faculty ratings of students applying to graduate school. Journal of Applied Measurement, 9, 168-181.

Klieger, D. M., Cline, F. A., Holtzman, S. L., Minsky, J. L., \& Lorenz, F. (2014). New perspectives on the validity of the GRE ${ }^{\circledR}$ General Test for predicting graduate school grades (GRE Board Research Report No. 14-03, ETS Research Report No. RR-14-26). Princeton, NJ: Educational Testing Service. https://doi.org/10.1002/ets2.12026

Kuncel, N. R., \& Hezlett, S. A. (2007). Standardized tests predict graduate students' success. Science, 315, 1080-81. https://doi.org/10.1126/science.1136618Kuncel, N. R., Hezlett, S. A., \& Ones, D. S. (2001). A comprehensive meta-analysis of the predictive validity of the graduate record examinations: Implications for graduate student selection and performance. Psychological Bulletin, 27, 162-181. https://doi.org/10.1037/0033-2909.127.1.162

Kuncel, N. R., Kochevar, R. J., \& Ones, D. S. (2014). A Meta-Analysis of letters of recommendation in college and graduate admissions: Reasons for hope. International Journal of Selection and Assessment, 22(1), 101-107. https://doi.org/10.1111/ijsa.12060

Kuncel, N. R., Wee, S., Serafin, L., \& Hezlett, S. A. (2010). The validity of the Graduate Record Examination for master's and doctoral programs: A meta-analytic investigation. Educational and Psychological Measurement, 70, 340-352. https://doi.org/10.1177/0013164409344508

Kyllonen, P. C. (2008). The research behind the ETS Personal Potential Index (PPI). Princeton, NJ: Educational Testing Service. Retrieved November 10, 2021 from https://citeseerx.ist.psu.edu/viewdoc/download?doi=10.1.1.522.5309\&rep=rep1\&type=pdf

Kyllonen, P. C., Walters, A. M., \& Kaufman, J. C. (2005). Noncognitive constructs and their assessment in graduate education. Educational Assessment, 10, 153-184. https://doi.org/10.1207/s15326977ea1003_2

Lin, F., Oh, S. K., Gordon, L. K., Pineles, S. L., Rosenberg, J. B., \& Tsui, I. (2019). Gender-based differences in letters of recommendation written for ophthalmology residency applicants. BMC Medical Education, 19(1), 476. https://doi.org/10.1186/s12909-019-1910-6

Liu, O. L., Minsky, J., Ling, G., \& Kyllonen, P. (2009). Using the standardized letters of recommendation in selection: Results from a multidimensional Rasch model. Educational and Psychological Measurement, 69(3), 475-492. https://doi.org/10.1177/0013164408322031

Madera, J. M., Hebl, M. R., Dial, H., Martin, R., \& Valian, V. (2019). Raising Doubt in Letters of Recommendation for Academia: Gender Differences and Their Impact. Journal of Business and Psychology, 34(3), 287-303. https://doi.org/10.1007/s10869-018-9541-1.

Madera, J. M., Hebl, M. R., \& Martin, R. C. (2009). Gender and letters of recommendation for academia: Agentic and communal differences. Journal of Applied Psychology, 94(6), 1591-1599. https://doi.org/10.1037/a0016539

McAbee, S., \& Oswald, F., \& Connelly, B. (2014). Bifactor models of personality and college student performance: A broad versus narrow view. European Journal of Personality, 28, 604-619. https://doi.org/10.1002/per.1975 
McCaffrey, D. F., Oliveri, M. E., \& Holtzman, S. (2018). A generalizability theory study to examine sources of score variance in third-party evaluations used in decision-making for graduate school admissions (GRE Board Research Report No. GRE-18-03). Princeton, NJ: Educational Testing Service. https://doi.org/10.1002/ets2.12225

McShane, B. B., Gal, D., Gelman, A., Robert, C., \& Tackett, J. L. (2019). Abandon statistical significance. The American Statistician, 73, 235-245. https://doi.org/10.1080/00031305.2018.1527253

Miller C., \& Stassun K. (2014). A test that fails. Nature, 510, 303-304.

Morgan, W. B., Elder, K. B., \& King, E. B. (2013). The emergence and reduction of bias in letters of recommendation: Bias in letters of recommendation. Journal of Applied Social Psychology, 43(11), 2297-2306. https://doi.org/10.1111/jasp.12179

Mosel, J. N., \& Goheen, H. W. (1959). The employment recommendation questionnaire: III. Validity of different types of references. Personnel Psychology, 12, 469-477. https://doi.org/10.1111/j.1744-6570.1959.tb01338.x

Nunnally, J. C. (1978). Psychometric theory (2nd ed.). McGraw-Hill.

Okahana, H., Zhou, E., \& Gao, J. (2020). Graduate enrollment and degrees: 2009 to 2019. Council of Graduate Schools. https://doi.org/10.1037/0021-9010.89.2.187

Oswald, F. L., Schmitt, N., Kim, B. H., Ramsay, L. J., \& Gillespie, M. A. (2004). Developing a biodata measure and situational judgment inventory as predictors of college student performance. Journal of Applied Psychology, 89, 187-207. https://doi.org/10.1037/0021-9010.89.2.187

Posselt, J. R. (2016). Inside graduate admissions: Merit, diversity, and faculty gatekeeping. Harvard University Press. https://doi.org/10.1353/rhe.2017.0026

Pyburn, K.M., Ployhart, R.E., \& Kravitz, D.A. (2008). The diversity-validity dilemma: Overview and legal context. Personnel Psychology, 61, 143-151. https://doi.org/10.1111/j.1744-6570.2008.00108.x

Rim, Y. (1976). How reliable are letters of recommendation? The Journal of Higher Education, 47, 437445. https://doi.org/10.1080/00221546.1976.11774065

Robin, F. (2014). Fairness and performance on the GRE revised General Test. In C. Wendler \& B. Bridgeman. The research foundation for the GRE revised General Test: A compendium of studies. Educational Testing Service.

Ryan, A. M., Ployhart, R. E., \& Friedel, L. A. (1998). Using personality testing to reduce adverse impact: A cautionary note. Journal of Applied Psychology, 83, 298-307. https://doi.org/10.1037/00219010.83.2.298

Sackett, P. R., \& Ellingson, J. E. (1997) The effects of forming multi-predictor composites on group differences and adverse impact. Personnel Psychology, 50, 707-721.

https://doi.org/10.1111/j.1744-6570.1997.tb00711.x 
Schmitt, N., Billington, A., Keeney, J., Oswald, F. L., Pleskac, T. J., Sinha, R., \& Zorzie, M. (2009). Prediction of four-year college student performance using cognitive and noncognitive predictors and the impact on demographic status of admitted students. Journal of Applied Psychology, 94, 1479-1497. https://doi.org/10.1037/a0016810

Schmitt, N., Clause, C. S., \& Pulakos, E. D. (1996). Group differences associated with different measures of some common job-relevant constructs. In C.L. Cooper and I. T. Robertson (Eds.), International Review of Industrial and Organizational Psychology (pp. 115-139). NY, NY: Wiley.

Schmitt, N., Rogers, W., Chan, D., Sheppard, L., \& Jennings, D. (1997). Adverse impact and predictive efficiency of various predictor combinations. Journal of Applied Psychology, 82, 719-730. https://doi.org/10.1037/0021-9010.82.5.719

Sedlacek, W. E. (2004). Beyond the big test: Noncognitive assessment in higher education. Jossey-Bass.

Seligman, A. I. (2012). Is graduate school really for you?: The whos, whats, hows, and whys of pursuing a master's or Ph.D. The Johns Hopkins University Press https://doi.org/10.1353/rhe.2013.0027

Shultz, M. M., \& Zedeck, S. (2018). Predicting lawyer effectiveness: Broadening the basis for law school admission decisions. Law \& Social Inquiry, 36, 620-661. https://doi:10.1111/j.17474469.2011.01245.x

Society for Industrial and Organizational Psychology, Inc. (2018). Principles for the validation and use of personnel selection procedures (5th. ed.).

Stark, S., Chernyshenko, O. S., \& Drasgow, F. (2012). Constructing fake-resistant personality tests using item response theory: High-stakes personality testing with multidimensional pairwise preferences. In M. Ziegler, C. MacCann, \& R. D. Roberts (Eds.), New perspectives on faking in personality assessment (pp. 214-239). Oxford University Press.

Thorndike R. L. (1949). Personnel selection; test and measurement techniques. Wiley.

Verostek, M., Miller, C., \& Zwickl, B. (2021). Analyzing admissions metrics as predictors of graduate GPA and whether graduate GPA mediates PhD completion. Physical Review Physics Education Research, 17, 020115. https://doi.org/10.1103/PhysRevPhysEducRes.17.020115

Walpole, M., Burton, N. W., Kanyi, K., \& Jackenthal, A. (2002). Selecting successful graduate students: Indepth interviews with GRE Users (Research Report No. 02-08). ETS. https://doi.org/10.1002/j.2333-8504.2002.tb01875.x

Warne, R. T., Yoon, M., \& Price, C. J. (2014). Exploring the various interpretations of "test bias." Cultural Diversity and Ethnic Minority Psychology, 20, 570-582. https://doi.org/10.1037/a0036503

Woo, S. E., LeBreton, J. M., Keith, M. G., \& Tay, L. (2020). Bias, fairness, and validity in graduate admissions: A psychometric perspective. Manuscript under review. Retrieved November 10, 2021 from https://psyarxiv.com/w5d7r/download/?format=pdf 


\section{Appendix A - PPI Dimensions and Items}

1. Knowledge and Creativity
a. Has a broad perspective on the field
b. Is among the brightest persons I know
c. Produces novel ideas
d. Is intensely curious about the field

2. Communication Skills
a. Speaks in a clear, organized and logical manner
b. Writes with precision and style
c. Speaks in a way that is interesting
d. Organizes writing well

3. Teamwork
a. Supports the efforts of others
b. Behaves in an open and friendly manner
c. Works well in group settings
d. Gives criticism/feedback to others in a helpful way

4. Resilience

a. Accepts feedback without getting defensive

b. Works well under stress

c. Can overcome challenges and setbacks

d. Works extremely hard

5. Planning and Organization
a. Sets realistic goals
b. Organizes work and time effectively
c. Meets deadlines
d. Makes plans and sticks to them

6. Ethics and Integrity
a. Is among the most honest persons I know
b. Maintains high ethical standards
c. Is worthy of trust from others
d. Demonstrates sincerity

Notes. Each item is rated on a 1 to 5 Likert scale, with 5 being the most favorable rating. 


\section{Table 1}

Description of Validity Sample

\begin{tabular}{|c|c|c|c|c|c|c|c|}
\hline \multicolumn{4}{|c|}{ Applied } & \multicolumn{4}{|c|}{ Enrolled: 33 programs only* } \\
\hline & & $\%$ & $\mathbf{n}$ & & & $\%$ & n \\
\hline \multirow[t]{2}{*}{ Gender } & Female & $57.10 \%$ & 2467 & Gender & Female & $63.90 \%$ & 445 \\
\hline & Male & $42.80 \%$ & 1850 & & Male & $36.10 \%$ & 251 \\
\hline \multirow[t]{9}{*}{ Race/Ethnicity } & American Indian/Alaska Native & $0.30 \%$ & 11 & Race/Ethnicity & American Indian/Alaska Native & $0.10 \%$ & 1 \\
\hline & Asian/Asian American & $1.80 \%$ & 77 & & Asian/Asian American & $1.30 \%$ & 9 \\
\hline & Black/African American & $8.10 \%$ & 348 & & Black/African American & $12.40 \%$ & 86 \\
\hline & Hispanic & $2.90 \%$ & 128 & & Hispanic & $2.10 \%$ & 15 \\
\hline & Native Hawaiian/Other Pacific Isl. & $0.10 \%$ & 4 & & Native Hawaiian/Other Pacific Isl. & $0.30 \%$ & 2 \\
\hline & Other & $1.50 \%$ & 63 & & Other & $1.00 \%$ & 7 \\
\hline & White (non-Hispanic) & $47.70 \%$ & 2061 & & White (non-Hispanic) & $53.00 \%$ & 369 \\
\hline & Missing & $37.70 \%$ & 1628 & & Missing & $29.70 \%$ & 207 \\
\hline & & Mean & SD & & & Mean & SD \\
\hline \multirow[t]{7}{*}{ PPI } & Knowledge \& Creativity & 4.00 & 0.52 & PPI & Knowledge \& Creativity & 3.98 & 0.49 \\
\hline & Communication Skills & 3.93 & 0.55 & & Communication Skills & 3.92 & 0.52 \\
\hline & Teamwork & 4.21 & 0.49 & & Teamwork & 4.21 & 0.49 \\
\hline & Resilience & 4.15 & 0.5 & & Resilience & 4.14 & 0.48 \\
\hline & Planning and Organization & 4.08 & 0.53 & & Planning and Organization & 4.05 & 0.51 \\
\hline & Ethics \& Integrity & 4.39 & 0.49 & & Ethics \& Integrity & 4.37 & 0.48 \\
\hline & Overall & 4.09 & 0.54 & & Overall & 4.07 & 0.51 \\
\hline \multirow[t]{3}{*}{ GRE } & Verbal & 151.32 & 7.67 & GRE & Verbal & 151.42 & 7.21 \\
\hline & Quantitative & 152.51 & 7.91 & & Quantitative & 151.07 & 7.95 \\
\hline & Analytical Writing & 3.71 & 0.84 & & Analytical Writing & 3.75 & 0.74 \\
\hline UGPA & UGPA & 3.39 & 0.43 & UGPA & UGPA & 3.40 & 0.42 \\
\hline
\end{tabular}

*Results of two-tailed t-tests indicated that no values were significantly different from a larger overall enrolled group in which some students had missing data and thus were excluded from analyses. 
Table 2

Mean Group Racial/Ethnic Differences on Cognitive and Socioemotional Skills

\begin{tabular}{|c|c|c|c|c|c|c|c|c|}
\hline & Measure & Minority Group & Cohen's $d$ & $95 \% \mathrm{Cl}$ & & $n_{1}$ & $n_{2}$ & $d f$ \\
\hline \multirow{21}{*}{ 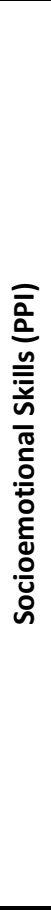 } & \multirow{3}{*}{ Knowledge \& Creativity } & Asian & 0.09 & {$[-0.01,0.18]$} & & 430 & 5402 & 5831 \\
\hline & & Black & -0.05 & {$[-0.14,0.03]$} & & 545 & 5402 & 5946 \\
\hline & & Hispanic & 0.02 & {$[-0.07,0.12]$} & & 510 & 5402 & 5911 \\
\hline & \multirow{3}{*}{ Communication Skills } & Asian & -0.01 & {$[-0.10,0.09]$} & & 430 & 5402 & 5831 \\
\hline & & Black & -0.06 & {$[-0.15,0.03]$} & & 545 & 5402 & 5946 \\
\hline & & Hispanic & 0.03 & {$[-0.06,0.12]$} & & 510 & 5402 & 5911 \\
\hline & \multirow{3}{*}{ Teamwork } & Asian & 0.14 & {$[0.04,0.24]$} & * & 430 & 5402 & 5831 \\
\hline & & Black & 0.12 & {$[0.03,0.21]$} & $*$ & 545 & 5402 & 5946 \\
\hline & & Hispanic & 0.08 & {$[-0.01,0.17]$} & & 510 & 5402 & 5911 \\
\hline & \multirow{3}{*}{ Resilience } & Asian & 0.10 & {$[0.00,0.20]$} & & 430 & 5402 & 5831 \\
\hline & & Black & 0.06 & {$[-0.03,0.15]$} & & 545 & 5402 & 5946 \\
\hline & & Hispanic & 0.07 & {$[-0.02,0.16]$} & & 510 & 5402 & 5911 \\
\hline & \multirow{3}{*}{ Planning \& Organization } & Asian & 0.10 & {$[0.01,0.20]$} & $*$ & 430 & 5402 & 5831 \\
\hline & & Black & -0.09 & {$[-0.18,0.00]$} & & 545 & 5402 & 5946 \\
\hline & & Hispanic & 0.01 & {$[-0.08,0.10]$} & & 510 & 5402 & 5911 \\
\hline & \multirow{3}{*}{ Ethics \& Integrity } & Asian & 0.06 & {$[-0.04,0.16]$} & & 430 & 5402 & 5831 \\
\hline & & Black & 0.03 & {$[-0.06,0.11]$} & & 545 & 5402 & 5946 \\
\hline & & Hispanic & 0.00 & {$[-0.09,0.09]$} & & 510 & 5402 & 5911 \\
\hline & \multirow{3}{*}{ Overall Evaluation } & Asian & 0.03 & {$[-0.07,0.13]$} & & 430 & 5402 & 5831 \\
\hline & & Black & -0.02 & {$[-0.11,0.07]$} & & 545 & 5402 & 5946 \\
\hline & & Hispanic & 0.01 & {$[-0.09,0.10]$} & & 510 & 5402 & 5911 \\
\hline \multirow{9}{*}{ 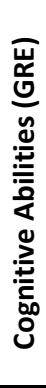 } & \multirow{3}{*}{ Verbal Reasoning } & Asian & -0.08 & {$[-0.17,0.02]$} & & 430 & 5402 & 5831 \\
\hline & & Black & -0.84 & {$[-0.93,-0.75]$} & $*$ & 545 & 5402 & 5946 \\
\hline & & Hispanic & -0.44 & {$[-0.53,-0.35]$} & $*$ & 510 & 5402 & 5911 \\
\hline & \multirow{3}{*}{ Quantitative Reasoning } & Asian & 0.50 & {$[0.40,0.60]$} & $*$ & 430 & 5402 & 5831 \\
\hline & & Black & -1.12 & {$[-1.21,-1.03]$} & $*$ & 545 & 5402 & 5946 \\
\hline & & Hispanic & -0.32 & {$[-0.41,-0.22]$} & $*$ & 510 & 5402 & 5911 \\
\hline & \multirow{3}{*}{ Analytical Writing } & Asian & -0.02 & {$[-0.12,0.08]$} & & 430 & 5402 & 5831 \\
\hline & & Black & -0.73 & {$[-0.82,-0.64]$} & $*$ & 545 & 5402 & 5946 \\
\hline & & Hispanic & -0.41 & {$[-0.50,-0.32]$} & $*$ & 510 & 5402 & 5911 \\
\hline \multirow{6}{*}{$\begin{array}{l}\frac{y}{\frac{\pi}{0}} \\
\frac{\pi}{0}\end{array}$} & \multirow{3}{*}{ Overall UGPA } & Asian & -0.42 & {$[-0.52,-0.32]$} & $*$ & 430 & 5402 & 5831 \\
\hline & & Black & -0.76 & {$[-0.85,-0.67]$} & $*$ & 545 & 5402 & 5946 \\
\hline & & Hispanic & -0.27 & {$[-0.36,-0.18]$} & $*$ & 510 & 5402 & 5911 \\
\hline & \multirow{3}{*}{ Major UGPA } & Asian & -0.53 & {$[-0.63,-0.43]$} & $*$ & 430 & 5402 & 5831 \\
\hline & & Black & -0.64 & {$[-0.73,-0.55]$} & $*$ & 545 & 5402 & 5946 \\
\hline & & Hispanic & -0.34 & {$[-0.43,-0.25]$} & $*$ & 510 & 5402 & 5911 \\
\hline
\end{tabular}

Notes. Data are from the PPI and are for U.S. citizens only. $95 \% \mathrm{Cl}=95 \%$ confidence interval for Cohen's $d ; n_{1}=$ sample size of minority group; $n_{2}=$ sample size of White group; $d f=$ degrees of freedom; a positive Cohen's $d$ indicates that the minority group had the higher mean score; where $95 \%$ confidence intervals for Cohen's $d$ fail to contain 0 (i.e., where an independent samples $t$-test with an alpha level of 0.05 would reject a null hypothesis of no mean difference between groups), the confidence interval is accompanied by an asterisk $\left({ }^{*}\right)$. 


\section{Table 3}

\section{Correlations and Adjusted Correlations}

\begin{tabular}{|c|c|c|c|c|c|c|c|c|c|c|c|c|c|}
\hline & \multirow[b]{2}{*}{ Measure } & \multirow[b]{2}{*}{ Group } & \multicolumn{5}{|c|}{ GGPA } & & \multicolumn{5}{|c|}{ Graduate School Grade Lower than a B } \\
\hline & & & $\mathbf{r}$ & $95 \% \mathrm{Cl}$ & & Adj $r$ & Adj $95 \% \mathrm{Cl}$ & & $\mathbf{r}$ & $95 \% \mathrm{Cl}$ & Adj $r$ & Adj $95 \% \mathrm{Cl}$ & \\
\hline \multirow{28}{*}{ 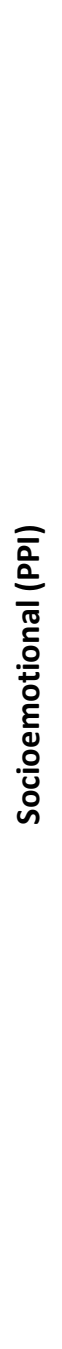 } & \multirow{5}{*}{$\begin{array}{l}\text { Knowledge \& } \\
\text { Creativity }\end{array}$} & Overall & 0.06 & {$[-0.06,0.17]$} & & 0.06 & {$[-0.05,0.18]$} & & 0.03 & {$[-0.08,0.15]$} & 0.03 & {$[-0.09,0.14]$} & \\
\hline & & Doctoral STEM & 0.11 & {$[-0.10,0.32]$} & & 0.12 & {$[-0.08,0.34]$} & & -0.05 & {$[-0.27,0.16]$} & -0.06 & {$[-0.29,0.14]$} & \\
\hline & & Doctoral Non-STEM & 0.01 & {$[-0.23,0.26]$} & & 0.00 & {$[-0.22,0.27]$} & & -0.02 & {$[-0.35,0.31]$} & -0.01 & {$[-0.36,0.30]$} & \\
\hline & & Master STEM & 0.04 & {$[-0.16,0.25]$} & & 0.04 & {$[-0.16,0.25]$} & & 0.04 & {$[-0.16,0.25]$} & 0.05 & {$[-0.16,0.25]$} & \\
\hline & & Master non-STEM & -0.01 & {$[-0.28,0.26]$} & & 0.01 & {$[-0.25,0.27]$} & & -0.10 & {$[-0.39,0.18]$} & 0.07 & {$[-0.40,0.16]$} & \\
\hline & \multirow{5}{*}{$\begin{array}{l}\text { Communication } \\
\text { Skills }\end{array}$} & Overall & 0.11 & {$[-0.02,0.23]$} & \multirow{5}{*}{$*$} & 0.11 & {$[-0.01,0.23]$} & & -0.07 & {$[-0.18,0.04]$} & -0.07 & {$[-0.18,0.04]$} & \multirow{5}{*}{$*$} \\
\hline & & Doctoral STEM & 0.17 & {$[0.00,0.35]$} & & 0.16 & {$[0.02,0.36]$} & $*$ & -0.20 & {$[-0.34,-0.06]$} & -0.21 & {$[-0.36,-0.08]$} & \\
\hline & & Doctoral Non-STEM & 0.03 & {$[-0.23,0.29]$} & & 0.03 & {$[-0.22,0.30]$} & & -0.22 & {$[-0.53,0.09]$} & -0.23 & {$[-0.53,0.08]$} & \\
\hline & & Master STEM & 0.09 & {$[-0.12,0.31]$} & & 0.09 & {$[-0.12,0.31]$} & & -0.04 & {$[-0.26,0.17]$} & -0.02 & {$[-0.26,0.17]$} & \\
\hline & & Master non-STEM & 0.10 & {$[-0.15,0.35]$} & & 0.11 & {$[-0.13,0.36]$} & & -0.09 & {$[-0.38,0.20]$} & -0.09 & {$[-0.39,0.18]$} & \\
\hline & \multirow{5}{*}{ Teamwork } & Overall & 0.05 & {$[-0.05,0.16]$} & & 0.05 & {$[-0.05,0.16]$} & & 0.02 & {$[-0.08,0.11]$} & 0.02 & {$[-0.08,0.11]$} & \\
\hline & & Doctoral STEM & 0.04 & {$[-0.17,0.26]$} & & 0.04 & {$[-0.17,0.26]$} & & -0.07 & {$[-0.26,0.12]$} & -0.08 & {$[-0.27,0.11]$} & \\
\hline & & Doctoral Non-STEM & 0.02 & {$[-0.17,0.21]$} & & 0.05 & {$[-0.17,0.21]$} & & 0.06 & {$[-0.02,0.14]$} & 0.05 & {$[-0.02,0.14]$} & \\
\hline & & Master STEM & -0.02 & {$[-0.25,0.20]$} & & -0.01 & {$[-0.25,0.20]$} & & 0.05 & {$[-0.17,0.27]$} & 0.05 & {$[-0.17,0.27]$} & \\
\hline & & Master non-STEM & 0.05 & {$[-0.16,0.26]$} & & 0.04 & {$[-0.16,0.26]$} & & -0.20 & {$[-0.48,0.07]$} & 0.08 & {$[-0.47,0.07]$} & \\
\hline & \multirow{5}{*}{ Resilience } & Overall & 0.05 & {$[-0.07,0.17]$} & & 0.05 & {$[-0.06,0.17]$} & & -0.01 & {$[-0.11,0.09]$} & -0.01 & {$[-0.12,0.09]$} & \\
\hline & & Doctoral STEM & 0.04 & {$[-0.20,0.29]$} & & 0.05 & {$[-0.18,0.30]$} & & -0.05 & {$[-0.21,0.11]$} & -0.08 & {$[-0.23,0.08]$} & \\
\hline & & Doctoral Non-STEM & 0.09 & {$[-0.12,0.30]$} & & 0.07 & {$[-0.12,0.31]$} & & -0.02 & {$[-0.20,0.17]$} & -0.01 & {$[-0.20,0.17]$} & \\
\hline & & Master STEM & 0.06 & {$[-0.18,0.29]$} & & 0.06 & {$[-0.18,0.29]$} & & -0.03 & {$[-0.26,0.20]$} & -0.02 & {$[-0.26,0.20]$} & \\
\hline & & Master non-STEM & -0.05 & {$[-0.29,0.18]$} & & -0.06 & {$[-0.28,0.19]$} & & -0.12 & {$[-0.39,0.15]$} & 0.01 & {$[-0.39,0.15]$} & \\
\hline & \multirow{5}{*}{$\begin{array}{l}\text { Planning \& } \\
\text { Organization }\end{array}$} & Overall & 0.12 & {$[0.01,0.22]$} & $*$ & 0.13 & {$[0.02,0.23]$} & $*$ & -0.08 & {$[-0.17,0.02]$} & -0.08 & {$[-0.18,0.01]$} & \\
\hline & & Doctoral STEM & 0.18 & {$[0.03,0.34]$} & $*$ & 0.17 & {$[0.06,0.36]$} & $*$ & -0.20 & {$[-0.34,-0.05]$} & -0.19 & {$[-0.36,-0.08]$} & \\
\hline & & Doctoral Non-STEM & 0.11 & {$[-0.07,0.29]$} & & 0.15 & {$[-0.06,0.3]$} & & -0.13 & {$[-0.33,0.07]$} & -0.17 & {$[-0.33,0.06]$} & \\
\hline & & Master STEM & 0.05 & {$[-0.16,0.25]$} & & 0.06 & {$[-0.16,0.25]$} & & 0.00 & {$[-0.22,0.22]$} & 0.01 & {$[-0.22,0.22]$} & \\
\hline & & Master non-STEM & 0.15 & {$[-0.04,0.35]$} & & 0.18 & {$\left[\begin{array}{lll}0.00 & 0.38\end{array}\right]$} & & -0.17 & {$[-0.35,0.01]$} & -0.20 & {$[-0.37,-0.03]$} & \\
\hline & \multirow{3}{*}{$\begin{array}{l}\text { Ethics \& } \\
\text { Integrity }\end{array}$} & Overall & 0.05 & {$[-0.04,0.15]$} & & 0.05 & {$[-0.04,0.15]$} & & 0.01 & {$[-0.08,0.11]$} & 0.02 & {$[-0.08,0.11]$} & \\
\hline & & Doctoral STEM & 0.07 & {$[-0.22,0.35]$} & & 0.08 & {$[-0.20,0.36]$} & & -0.08 & {$[-0.22,0.05]$} & -0.10 & {$[-0.23,0.03]$} & \\
\hline & & Doctoral Non-STEM & 0.14 & {$[-0.07,0.34]$} & & 0.18 & {$[-0.07,0.34]$} & & 0.10 & {$[-0.11,0.30]$} & 0.07 & {$[-0.11,0.30]$} & \\
\hline
\end{tabular}




\begin{tabular}{|c|c|c|c|c|c|c|c|c|c|c|c|c|c|c|}
\hline & & Master STEM & -0.01 & {$[-0.20,0.18]$} & & -0.01 & {$[-0.20,0.18]$} & & 0.09 & {$[-0.13,0.30]$} & & 0.09 & {$[-0.13,0.30]$} & \\
\hline & & Master non-STEM & 0.05 & {$[-0.17,0.26]$} & & 0.05 & {$[-0.17,0.26]$} & & -0.11 & {$[-0.33,0.12]$} & & -0.09 & {$[-0.33,0.12]$} & \\
\hline & & Overall & 0.06 & {$[-0.05,0.17]$} & & 0.07 & {$[-0.04,0.18]$} & & 0.00 & {$[-0.10,0.11]$} & & 0.00 & {$[-0.11,0.10]$} & \\
\hline & & Doctoral STEM & 0.12 & {$[-0.09,0.34]$} & & 0.13 & {$[-0.06,0.35]$} & & -0.12 & {$[-0.30,0.06]$} & & -0.14 & {$[-0.31,0.03]$} & \\
\hline & & Doctoral Non-STEM & 0.06 & {$[-0.16,0.27]$} & & 0.07 & {$[-0.14,0.28]$} & & -0.03 & {$[-0.29,0.22]$} & & -0.08 & {$[-0.29,0.21]$} & \\
\hline & & Master STEM & 0.05 & {$[-0.17,0.28]$} & & 0.06 & {$[-0.17,0.28]$} & & 0.01 & {$[-0.22,0.23]$} & & 0.01 & {$[-0.22,0.23]$} & \\
\hline & & Master non-STEM & 0.00 & {$[-0.23,0.24]$} & & 0.03 & {$[-0.20,0.25]$} & & -0.09 & {$[-0.38,0.20]$} & & 0.07 & {$[-0.39,0.17]$} & \\
\hline \multirow{15}{*}{ 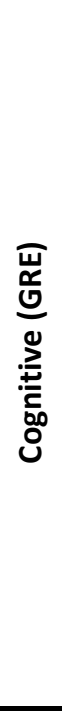 } & \multirow{5}{*}{$\begin{array}{l}\text { Verbal } \\
\text { Reasoning }\end{array}$} & Overall & 0.21 & {$[0.12,0.30]$} & $*$ & 0.23 & {$[0.13,0.32]$} & $*$ & -0.12 & {$[-0.20,-0.03]$} & * & -0.13 & {$[-0.21,-0.04]$} & * \\
\hline & & Doctoral STEM & 0.17 & {$[-0.07,0.41]$} & & 0.19 & {$[-0.07,0.41]$} & & -0.13 & {$[-0.31,0.05]$} & & -0.13 & {$[-0.32,0.05]$} & \\
\hline & & Doctoral Non-STEM & 0.33 & {$[0.12,0.54]$} & $*$ & 0.37 & {$[0.14,0.6]$} & * & -0.06 & {$[-0.39,0.28]$} & & -0.09 & {$[-0.44,0.31]$} & \\
\hline & & Master STEM & 0.28 & {$[0.11,0.45]$} & * & 0.29 & {$[0.12,0.48]$} & * & -0.18 & {$[-0.28,-0.09]$} & * & -0.19 & {$[-0.31,-0.10]$} & * \\
\hline & & Master non-STEM & 0.06 & {$[-0.17,0.28]$} & & 0.07 & {$[-0.18,0.30]$} & & -0.15 & {$[-0.42,0.12]$} & & -0.07 & {$[-0.45,0.13]$} & \\
\hline & \multirow{5}{*}{$\begin{array}{l}\text { Quantitative } \\
\text { Reasoning }\end{array}$} & Overall & 0.26 & {$[0.18,0.34]$} & $*$ & 0.28 & {$[0.20,0.38]$} & $*$ & -0.17 & {$[-0.27,-0.07]$} & $*$ & -0.19 & {$[-0.30,-0.08]$} & * \\
\hline & & Doctoral STEM & 0.21 & {$[0.04,0.38]$} & $*$ & 0.22 & {$[0.04,0.41]$} & * & -0.12 & {$[-0.34,0.10]$} & & -0.10 & {$[-0.37,0.11]$} & \\
\hline & & Doctoral Non-STEM & 0.19 & {$[-0.08,0.47]$} & & 0.21 & {$[-0.11,0.56]$} & & 0.02 & {$[-0.33,0.37]$} & & -0.01 & {$[-0.41,0.45]$} & \\
\hline & & Master STEM & 0.27 & {$[0.09,0.44]$} & $*$ & 0.29 & {$[0.09,0.46]$} & $*$ & -0.21 & {$[-0.39,-0.03]$} & $*$ & -0.24 & {$[-0.42,-0.03]$} & * \\
\hline & & Master non-STEM & 0.34 & {$[0.13,0.54]$} & $*$ & 0.35 & {$[0.14,0.56]$} & $*$ & -0.31 & {$[-0.52,-0.09]$} & $*$ & -0.32 & {$[-0.54,-0.1]$} & * \\
\hline & \multirow{5}{*}{$\begin{array}{l}\text { Analytical } \\
\text { Writing }\end{array}$} & Overall & 0.17 & {$[0.05,0.28]$} & $*$ & 0.18 & {$[0.06,0.31]$} & * & -0.13 & {$[-0.23,-0.03]$} & $*$ & -0.14 & {$[-0.30,-0.08]$} & * \\
\hline & & Doctoral STEM & 0.15 & {$[-0.06,0.37]$} & & 0.17 & {$[-0.06,0.38]$} & & -0.10 & {$[-0.30,0.11]$} & & -0.11 & {$[-0.32,0.11]$} & \\
\hline & & Doctoral Non-STEM & 0.15 & {$[-0.13,0.43]$} & & 0.15 & {$[-0.16,0.53]$} & & -0.17 & {$[-0.41,0.07]$} & & -0.22 & {$[-0.50,0.09]$} & \\
\hline & & Master STEM & 0.18 & {$[0.01,0.35]$} & $*$ & 0.18 & {$[0.00,0.38]$} & * & -0.17 & {$[-0.33,-0.02]$} & $*$ & -0.19 & {$[-0.36,-0.02]$} & * \\
\hline & & Master non-STEM & 0.19 & {$[0.02,0.37]$} & $*$ & 0.18 & {$[0.02,0.39]$} & * & -0.25 & {$[-0.57,0.07]$} & & -0.13 & {$[-0.6,0.08]$} & \\
\hline \multirow{5}{*}{$\begin{array}{l}\text { đ } \\
\frac{\pi}{\pi} \\
\frac{\pi}{5}\end{array}$} & \multirow{5}{*}{ UGPA } & Overall & 0.29 & {$[0.20,0.39]$} & $*$ & 0.31 & {$[0.05,0.28]$} & $*$ & -0.24 & {$[-0.34,-0.13]$} & $*$ & -0.25 & {$[-0.37,-0.13]$} & * \\
\hline & & Doctoral STEM & 0.34 & {$[0.06,0.62]$} & $*$ & 0.46 & {$[0.06,0.63]$} & * & -0.34 & {$[-0.57,-0.11]$} & $*$ & -0.34 & {$[-0.58,-0.11]$} & * \\
\hline & & Doctoral Non-STEM & 0.22 & {$[-0.01,0.46]$} & & 0.23 & {$[-0.01,0.48]$} & & -0.18 & {$[-0.45,0.08]$} & & -0.24 & {$[-0.47,0.09]$} & \\
\hline & & Master STEM & 0.15 & {$[0.06,0.24]$} & $*$ & 0.16 & {$[0.07,0.27]$} & $*$ & -0.10 & {$[-0.30,0.09]$} & & -0.11 & {$[-0.33,0.1]$} & \\
\hline & & Master non-STEM & 0.43 & {$[0.25,0.62]$} & * & 0.46 & {$[0.27,0.65]$} & * & -0.43 & {$[-0.61,-0.25]$} & 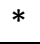 & -0.44 & {$[-0.64,-0.27]$} & * \\
\hline
\end{tabular}

Notes. Ns (numbers of individuals in analyses) \& ks (numbers of programs in analyses) for GGPA. Overall $=696 \& 32$, Doctoral STEM $=151 \& 9$, Doctoral Non-STEM $=102 \& 11$, Master STEM $=273 \& 13$, Master Non-STEM $=128$ \& 14. Ns \& ks for B for Grad School Grade Lower than B. Overall = 617 \& 23, Doctoral STEM = 151 \& 9, Doctoral Non-STEM = 48 \& 5, Master STEM = 267 \& 12, Master Non-STEM $=93$ \& 9. The correlations for GGPA are Pearson Product Moment; for Graduate School Grade Lower than a B, they are point-biserial. For Grad School Grade Below $B$, a negative correlation indicates that higher performance on the predictor is associated with lower frequency of receiving a B. Adj = PPI adjusted for indirect range restriction and GRE and UGPA for direct range restriction (Thorndike, 1949). * indicates $95 \%$ confidence intervals omitting 0 , equivalent to a 2 -tailed statistical significance test for zero-order correlations rejecting the null hypothesis that $r=0$, with $p<.05$. 


\section{Table 4}

Intercorrelations Sample-Size Weighted Across Programs $(N=696)$

\begin{tabular}{|c|c|c|c|c|c|c|c|c|c|c|c|c|c|}
\hline & & & \multicolumn{7}{|c|}{ SOCIOEMOTIONAL (PPI) } & \multicolumn{3}{|c|}{ COGNITIVE (GRE) } & \multirow{2}{*}{$\begin{array}{l}\text { MIXED } \\
\text { UPGA }\end{array}$} \\
\hline & Measure & Analysis & $\begin{array}{l}\text { Knowledge } \\
\text { \& Creativity }\end{array}$ & $\begin{array}{l}\text { Communicat } \\
\text { ion Skills }\end{array}$ & Teamwork & Resilience & $\begin{array}{l}\text { Planning \& } \\
\text { Organizatio } \\
\mathrm{n}\end{array}$ & $\begin{array}{l}\text { Ethics \& } \\
\text { Integrity }\end{array}$ & $\begin{array}{l}\text { Overall } \\
\text { Evaluation }\end{array}$ & $\begin{array}{l}\text { Verbal } \\
\text { Reasoning }\end{array}$ & $\begin{array}{l}\text { Quantitativ } \\
\text { e Reasoning }\end{array}$ & $\begin{array}{l}\text { Analytical } \\
\text { Writing }\end{array}$ & \\
\hline \multirow{13}{*}{ 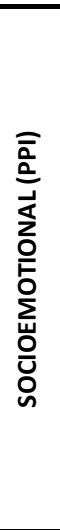 } & $\begin{array}{l}\text { Knowledge } \\
\text { \& Creativity }\end{array}$ & $\begin{array}{l}\mathrm{r} \\
95 \% \mathrm{Cl}\end{array}$ & -- & $\begin{array}{r}0.81 \\
{[0.76,0.87]}\end{array}$ & $\begin{array}{r}0.71 \\
{[0.63,0.79]}\end{array}$ & $\begin{array}{r}0.76 \\
{[0.68,0.84]}\end{array}$ & $\begin{array}{r}0.73 \\
{[0.66,0.8]}\end{array}$ & $\begin{array}{r}0.67 \\
{[0.59,0.74]}\end{array}$ & $\begin{array}{r}0.83 \\
{[0.78,0.87]}\end{array}$ & $\begin{array}{r}0.06 \\
{[-0.03,0.16]}\end{array}$ & $\begin{array}{r}0.08 \\
{[-0.03,0.19]}\end{array}$ & $\begin{array}{r}0.05 \\
{[-0.05,0.15]}\end{array}$ & $\begin{array}{r}0.22 \\
{[0.14,0.31]}\end{array}$ \\
\hline & Communicat & $r$ & & -- & 0.72 & 0.75 & 0.76 & 0.63 & 0.78 & 0.18 & 0.08 & 0.12 & 0.20 \\
\hline & ion & $95 \% \mathrm{Cl}$ & & & {$[0.66,0.78]$} & {$[0.70,0.80]$} & {$[0.71,0.8]$} & {$[0.58,0.68]$} & {$[0.73,0.83]$} & {$[0.08,0.27]$} & {$[-0.02,0.18]$} & {$[0.02,0.22]$} & {$[0.11,0.29]$} \\
\hline & Teamwork & $r$ & & & -- & 0.82 & 0.73 & 0.74 & 0.71 & 0.02 & -0.02 & 0.01 & 0.13 \\
\hline & Teamwork & $95 \% \mathrm{Cl}$ & & & & {$[0.78,0.85]$} & {$[0.67,0.79]$} & {$[0.7,0.78]$} & {$[0.63,0.79]$} & {$[-0.06,0.1]$} & {$[-0.12,0.09]$} & {$[-0.1,0.12]$} & {$[0.02,0.23]$} \\
\hline & Recilience & $r$ & & & & -- & 0.82 & 0.74 & 0.77 & 0.03 & -0.01 & 0.03 & 0.17 \\
\hline & Resillence & $95 \% \mathrm{Cl}$ & & & & & {$[0.76,0.88]$} & {$[0.69,0.80]$} & {$[0.68,0.86]$} & {$[-0.06,0.11]$} & {$[-0.12,0.1]$} & {$[-0.06,0.13]$} & {$[0.05,0.28]$} \\
\hline & Planning \& & $r$ & & & & & -- & 0.69 & 0.76 & 0.02 & 0.01 & 0.03 & 0.24 \\
\hline & Organization & $95 \% \mathrm{Cl}$ & & & & & & {$[0.62,0.75]$} & {$[0.71,0.82]$} & {$[-0.07,0.11]$} & {$[-0.09,0.11]$} & {$[-0.05,0.11]$} & {$[0.15,0.33]$} \\
\hline & Ethics \& & $r$ & & & & & & -- & 0.70 & 0.05 & 0.01 & -0.03 & 0.09 \\
\hline & Integrity & $95 \% \mathrm{Cl}$ & & & & & & & {$[0.63,0.76]$} & {$[-0.03,0.12]$} & {$[-0.07,0.09]$} & {$[-0.12,0.06]$} & {$[0.01,0.17]$} \\
\hline & Overall & $r$ & & & & & & & -- & 0.06 & 0.05 & 0.04 & 0.20 \\
\hline & Evaluation & $95 \% \mathrm{Cl}$ & & & & & & & & {$[-0.03,0.15]$} & {$[-0.06,0.16]$} & {$[-0.06,0.14]$} & {$[0.12,0.29]$} \\
\hline \multirow{6}{*}{ 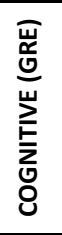 } & Verbal & $r$ & & & & & & & & -- & 0.43 & 0.46 & 0.21 \\
\hline & Reasoning & $95 \% \mathrm{Cl}$ & & & & & & & & & {$[0.33,0.52]$} & {$[0.38,0.53]$} & {$[0.11,0.31]$} \\
\hline & Quantitative & $r$ & & & & & & & & & -- & 0.19 & 0.18 \\
\hline & Reasoning & $95 \% \mathrm{Cl}$ & & & & & & & & & & {$[0.1,0.28]$} & {$[0.07,0.28]$} \\
\hline & Analytical & $r$ & & & & & & & & & & -- & 0.14 \\
\hline & Writing & $95 \% \mathrm{Cl}$ & & & & & & & & & & & {$[0.05,0.23]$} \\
\hline 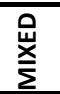 & UGPA & $\begin{array}{l}r \\
95 \% \mathrm{Cl}\end{array}$ & & & & & & & & & & & -- \\
\hline
\end{tabular}




\section{Table 5}

Hierarchical Linear Modeling Results with Level 1 Predictors of GGPA: Predictive Validity of UGPA, GRE, and PPI

\begin{tabular}{lllll}
\hline \multicolumn{5}{c}{ Model } \\
\hline 1 & 2 & 3 & 4 &
\end{tabular}

$$
\text { Yoo }
$$

UGPA

GRE Verbal

GRE Quantitative

GRE Analytical Writing

PPI Knowledge \& Creativity

PPI Communications Skills

PPI Teamwork

PPI Resilience

PPI Planning \& Organization

PPI Ethics \& Integrity

PPI Overall

Variance Components

$$
\tau_{00}
$$

$$
\sigma^{2}
$$

Reduction in within level variance

vs. Model 1

vs. Model 2

vs. Model 3

Fit of the model

-2LogLikelihood

$\Delta$ Deviance (vs the previous model)
$3.79(0.03)^{* * *}$

\section{$3.79(0.03)^{* * *}$}

$0.18(0.02)^{* * *}$

$$
\begin{aligned}
& 3.79(0.03)^{* * *} \\
& 0.14(0.02)^{* * *} \\
& 0.00(0.00) \\
& 0.01(0.00)^{* * *} \\
& 0.03(0.02)^{*}
\end{aligned}
$$$$
0.02(0.01)^{* * *}
$$$$
0.07(0.00) * * *
$$

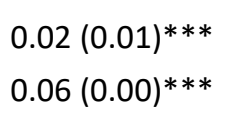

$7.14 \%$

$-$

163.74

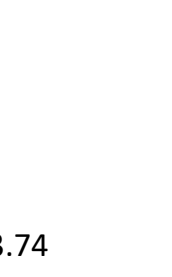

$3.79(0.03)^{* * *}$

$0.14(0.03)^{* * *}$

$0.00(0.00)$

$0.01(0.00)^{* * *}$

$0.03(0.02)$

$-0.10(0.04)^{*}$

$0.03(0.04)$

$0.02(0.04)$

$-0.06(0.05)$

$0.12(0.04)^{* *}$

$0.00(0.03)$

$-0.02(0.04)$

$0.02(0.01)^{* * *}$

$0.06(0.00)^{* * *}$

$0.06(0.00)^{* * *} \quad 0.06(0.00)^{* * *}$

$11.67 \% \quad 13.70 \%$

$4.90 \% \quad 7.06 \%$

$2.23 \%$
114.16
80.67
$33.49(3)^{* * *}$

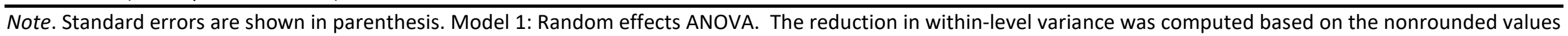

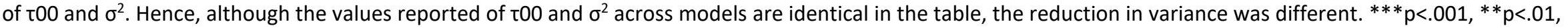
$*_{p}<.05$ 


\section{Table 6}

Results of a Generalized Estimating Equation Logistic Regression Predicting the Likelihood of Receiving a Grade Below B

\begin{tabular}{|c|c|c|c|c|c|c|c|c|}
\hline Predictor & $\beta$ & SE $\beta$ & $95 \% \mathrm{C}$ & $\begin{array}{l}\text { idence } \\
\text { is }\end{array}$ & Z & $p$ & $\begin{array}{c}\mathrm{e}^{\beta} \\
\text { (odds } \\
\text { ratio) }\end{array}$ & $\begin{array}{c}\text { Percentage Increase (+) or } \\
\text { Decrease (-) in Likelihood of } \\
\text { Receiving a Grade Below a B } \\
\text { That Can Be Expected from a } \\
\text { 1-Unit Increase in the } \\
\text { Predictor }\end{array}$ \\
\hline Intercept & 5.89 & 3.19 & -0.37 & 12.15 & 1.84 & 0.07 & 362.17 & -- \\
\hline $\begin{array}{l}\text { PPI Knowledge \& } \\
\text { Creativity }\end{array}$ & 1.39 & 0.36 & -0.68 & -2.10 & 3.81 & 0.00 & 4.02 & $+302 \%$ \\
\hline PPI Communication & -1.09 & 0.46 & -1.98 & -0.19 & -2.38 & 0.02 & 0.34 & $-66 \%$ \\
\hline PPI Teamwork & -0.43 & 0.37 & -0.29 & 1.15 & 1.16 & 0.25 & 0.65 & $-35 \%$ \\
\hline PPI Resilience & 0.10 & 0.41 & -0.71 & 0.91 & 0.24 & 0.81 & 1.11 & $+11 \%$ \\
\hline $\begin{array}{l}\text { PPI Planning \& } \\
\text { Organization }\end{array}$ & -0.94 & 0.52 & -1.95 & 0.07 & -1.82 & 0.07 & 0.39 & $-61 \%$ \\
\hline PPI Ethics \& Integrity & -0.07 & 0.37 & -0.79 & 0.64 & -0.20 & 0.84 & 0.93 & $-7 \%$ \\
\hline PPI Overall & 0.12 & 0.56 & -0.97 & 1.22 & 0.22 & 0.83 & 1.13 & $+13 \%$ \\
\hline GRE Verbal & 0.01 & 0.02 & -0.03 & 0.04 & 0.33 & 0.74 & 1.01 & $+1 \%$ \\
\hline GRE Quantitative & -0.02 & 0.01 & -0.05 & 0.01 & -1.30 & 0.19 & 0.98 & $-2 \%$ \\
\hline $\begin{array}{l}\text { GRE Analytical } \\
\text { Writing }\end{array}$ & -0.42 & 0.17 & -0.76 & -0.08 & -2.44 & 0.01 & 0.66 & $-34 \%$ \\
\hline UGPA & -1.12 & 0.26 & 1.63 & 0.6 & -4.25 & $<.0001$ & 0.33 & $-67 \%$ \\
\hline
\end{tabular}




\section{Figure 1}

Minority Admission Rates for the Most Selective Institutions - Selection of Top 15\% of Applicant Pool

\section{Entire Applicant}

Pool

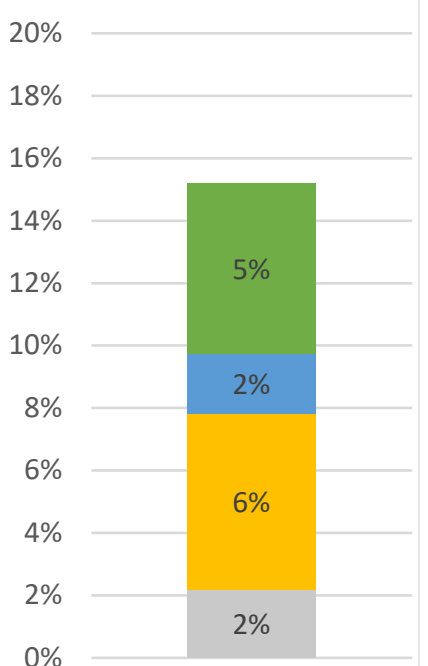

GRE + UGPA and PPI Planning and Organization at 15\% Selectivity

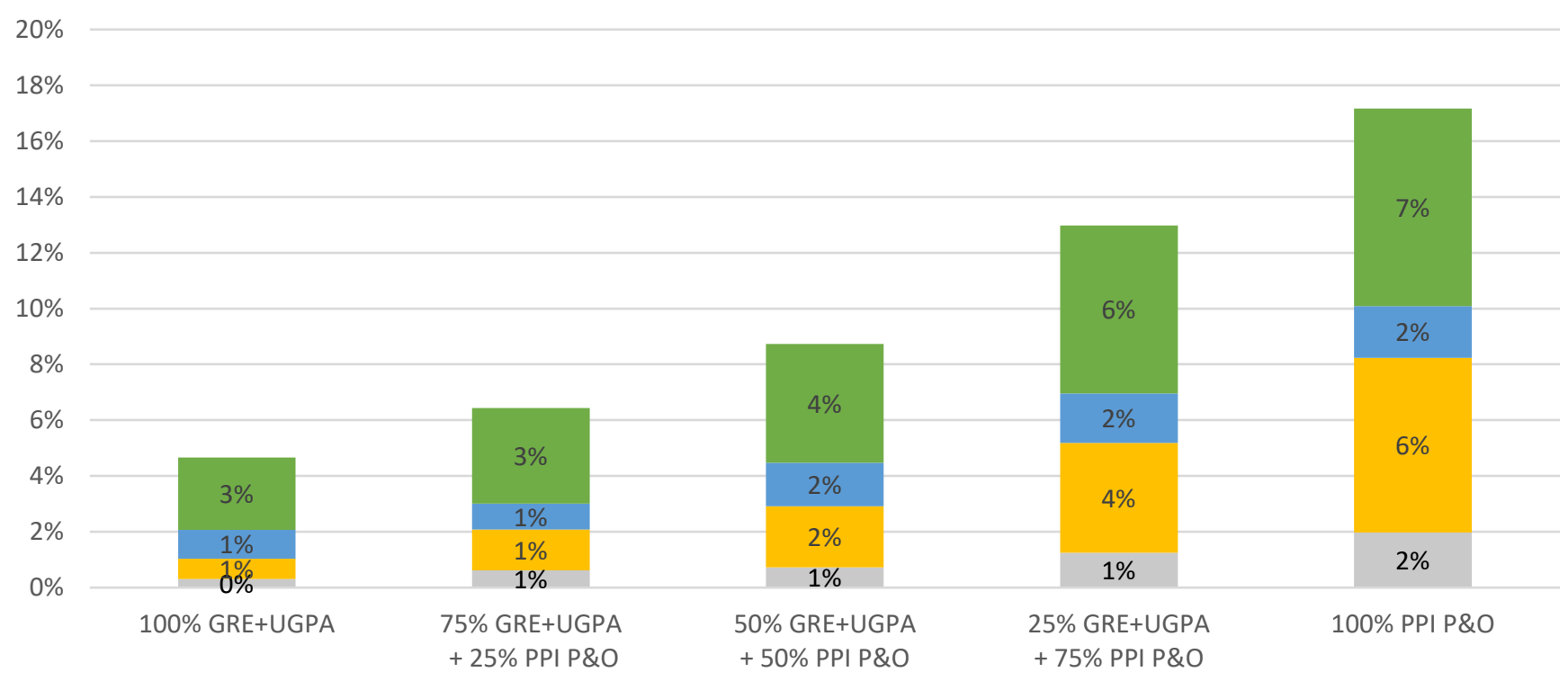

Black or African American Male $\quad$ Black or African American Female $\quad$ Hispanic Male $\quad$ Hispanic Female

Notes. Data are for U.S. citizens only. American Indian/Alaskan Native and Hawaiian and other Pacific Islander groups are unreported because of their small sample sizes $(\mathrm{N} \leq 5)$.. Given their relatively large percentages of the applicant pool, non-Hispanic White and Asian/Asian-American groups are unreported here in order to make the bar graph more legible. "Entire Applicant Pool" = percentage of entire applicant pool ( $N=6,414$ when including non-Hispanic White individuals) self-identifying as a member of that group and expected selection ratios when admissions is purely random or is based solely on proportionality to race/ethnicity-gender composition of applicant pool. "GRE+UGPA" = selection using GRE Verbal + Quantitative + Analytical Writing, equally weighted after standardization of scores, then added to equally weighted UGPA after re-standardization). "PPI PPO" = selection using PPI Planning \& Organization. Percentages in the $x$-axis labels indicate component weights after standardization of the information being added together. 